ample, the heartio, so that adequate blood-levels were not maintained. In vitro experiments with mammary gland slices have now provided what we believe to be the first evidence in favour of the new theory of the origin of milk fat (see accompanying table).

Lactating mammary gland slices from all nonruminants studied-rat ${ }^{11}$, mouse, rabbit and guinea pig-have given a high respiratory quotient (measured as before ${ }^{11}$ ) in the presence of glucose, indicating the probable formation of fat from carbohydrate; on the other hand, the respiratory quotient for slices from the goat (and cow) is well below unity. With acetate as substrate, however, the situation is reversed, goat (and cow) gland now giving a respiratory quotient greater than unity, whereas the rat (and mouse) mammary gland do not appear to utilize acetate. The mammary tissue of the ruminant thus appears to be adapted for metabolizing acetate ; and can not only oxidize it, but also, as indicated by the high respiratory quotient in vitro, can probably utilize it for fat synthesis, in this respect differing from other mammals, exemplified by the rat, which appear to require carbohydrate as substrate for fat formation. These results are consistent with the theory that in ruminants part of the milk fat is synthesized from acetate (this would explain the high udder respiratory quotient in vivo $0^{3,11}$ ); and if this is so, it seems very likely that the short-chain acids in particular arise in this way.

\section{S. J. Folley}

T. H. FRENCH

National Institute for Research in Dairying, Shinfield, near Reading. Oct. 16.

${ }^{1}$ Hilditch, T. P., Analyst, 62, 250 (1937).

'Shaw. J. C., and Petersen, W. E., Amer. J. Physiol., 128, 183 P (1938).

${ }^{8}$ Reineke, E. P., Stonecipher, W. D., and Turner, C. W., Amer. J. Physiol., 132, 535 (1941).

"Hilditch, T. P., "The Chemical Constitution of Natural Fats", 2nd Edit. (Iondon, 1947).

${ }^{5}$ Elsden, S. R., Proc. Roy. Soc. Med., 39, 802 (1946)

'Rittenberg, D., and Bloch, K., J. Biol. Chem., 160, 417 (1945).

'Folley, S. J., in “Marshall's Physiology of Reproduction", 3rd Edit. (edited by A. S. Parkes), Chap. 20 (in the press).

- Folley, S. J., and Malpress, F. H., unpublished results. See Malpress, F. H. Proc. Roy Soc, Med, 39, 805 (1946).

'Mann, A. I., and Shaw, J. C., J. Dairy Sci., 30, 183 (1947).

${ }^{10}$ Lorber, V., Lifson, N., Wood, H. G., and Barcroft, J., Amer. J. Physiol., 145, 557 (1946).

${ }^{"}$ Folley, S. J., and French, T. H., Nature, 161, 933 (1948).

\section{Criteria of Relationship between Plant Virus Strains}

IT is now generally recognized that cross-protective power in the host plant, and serological relationship, are two of the most satisfactory criteria for establishing relationship between plant viruses.

In spite of an early observation by $\mathrm{Smith}^{1}$, it is usually considered that if two viruses are related strains, then one strain will protect a plant com. pletely from infection by a second strain, provided that the plant is fully infected with the first strain before inoculation with the second.

In experiments in Datura tatula and tobacco with six mottle type and four ring-spot type strains of potato virus $X$, it was found that four of the mottle strains protected completely against all the ring-spot strains. However, with two strains of the mottle type ( $B$ from Duke of York potato ${ }^{2}$ and $T B R X$ from tomato $^{3}$ ), necrotic local lesions and systemic necrosis developed following inoculation with any of the ringspot strains used. However, symptoms were not as severe as in the healthy controls inoculated with the ring-spot strains.

The same set of ten strains was also examined by the serological cross-absorption technique. Six of the strains were indistinguishable by the method used. Two strains had been isolated from the same potato plant, one a symptomless and one a ring-spot type isolated from Salaman's $X^{h}$ culture ${ }^{4}$. These two strains were serologically indistinguishable, but possessed an antigenic fraction not possessed by any of the other eight strains. Thus, in this case, serological relationship was correlated with source of origin rather than symptom type.

$T B R X$ and $B$, the two strains that did not give complete protection in the host, differed considerably in the serological tests from any of the other strains. They each had a strain-specific antigenic fraction and also shared a fraction not possessed by any of the other eight strains tested.

Thus, within the group of ten strains tested, there was a correlation between serological relationship and the degree of protection afforded in the host plant.

R. E. F. MATTHEWS

Plant Virus Research Unit, Molteno Institute, Cambridge. Dec. 7.

'Smith, K. M., Biol. Rev., 8, 136 (1933).

Bawden, F. C., and Sheffleld, F. M. L., Ann. App. Biol., 81, 38 (1944).

- Smith, K. M., Parasitology, 37, 126 (1946)

- Salaman, R. N., Phil. Trans. Roy. Soc., B, 229, 137 (1938).

\section{Infectious Chlorosis of Bananas in Colombia}

A DISEASE probably identical or closely allied to the 'infectious chlorosis' or 'heart rot' of bananas, of a virus nature, has recently been found in Cauca Valley, on the Pacific side of Colombia, South America, and is now being studied by the staff of the Agricultural Experimental Station of Palmira.

This is a new record of the disease, previously known, in America, in the islands of Guadeloupe and Haiti ${ }^{1}$. Australian and African records have been reported by Wardlaw2.

This is also the second time that a virus disease of cultivated plants has been found in Hispaniola Island (Haiti and Dominican Republics) and Cauca Valley, Colombia. I have already published previous records of a disease of the cacao tree of the same geographical distribution ${ }^{3}$.

The features of this banana disease coincide with the symptoms described by Magee, Morwood and Wardlaw, with the exception of linear spots (from midrib to margin), which are frequently brown or reddish, instead of chlorotic. This symptom appears to be correlated with the presence of anthocyanin pigment in the leaves.

Italian Cryptogamic Laboratory,

R. CIFERRI

Botanic Institute,

University, Pavia.

Dec. 8.

1 Wardlaw, C. W., Trop. Agric., 14, 10 (1937); 15, 276 (1938).

Wardlaw, C. W., Nature, 162, 894 (1948).

- Ciferri, R., Rev. Fac. Nac. de Agr. de Medellin, 8, 79 (1948). 